\title{
Correction to: Silvicultural prescriptions for mixed-species forest stands. A European review and perspective
}

\author{
Hans Pretzsch ${ }^{1}(1) \cdot$ Werner Poschenrieder ${ }^{1} \cdot$ Enno Uhl $^{1,2} \cdot$ Gediminas Brazaitis $^{3}$. Ekaterina Makrickiene ${ }^{3}$. \\ Rafael Calama ${ }^{4}$
}

Published online: 26 July 2021

○) Springer-Verlag GmbH Germany, part of Springer Nature 2021

Correction to: European Journal of Forest Research https://doi.org/10.1007/s10342-021-01388-7

In this article, the wrong figure appeared as Fig. 4; the Fig. 4 should have appeared as shown in below.

The original article has been corrected.

The original article can be found online at https://doi.org/10.1007/ s10342-021-01388-7.

Hans Pretzsch

Hans.Pretzsch@tum.de

1 Chair for Forest Growth and Yield Science, School of Life Sciences, Technical University of Munich, Hans-Carl-von-Carlowitz-Platz 2, 85354 Freising, Germany

2 Bavarian Institute of Forestry, Hans-Carl-von-Carlowitz-Platz 1, 85354 Freising, Germany

3 Institute of Forest Biology and Silviculture, Vytautas Magnus University Studentu, str. 11 Akademijos mstl. Kaunas dist. LT-53361, Lithuania

4 Department of Forest Dynamics and Management,

INIA-Forest Research Centre. iuFOR UVa-INIA, Ctra. A

Coruña km 7.5, 28040 Madrid, Spain 
Fig. 4 Technical concepts of treatment implementation: concept 1 is typical for succession models, physiological or matrix models within their original field of application: thinning is an exclusive result of natural mortality; concept 2 is typical for models of concept 1 when extended for application in forestry: tree removal is an effect of thinning in addition, based on a thinning curve or a percentage of maximum density; concept 3 is typical for stand simulators when applied in education or consulting: the user selects from a group of alternative treatments, each time the system has come to a particular target state, e.g., given through stand age; concept 4 is typical for simulators applied within larger scale studies related to a whole forest management unit or landscape: the simulator determines the stand's developmental state based on stand statistics, such as a top height or the QMD and based on that current state selects a treatment rule, in order to approach a desired development. Simulator concept 5 is an extension to concept 4 that compares the stand's state (e.g., height, species composition) to a database that holds treatment instructions as dependent on stand state. The optimizer concept 6 embeds concept 5 into an optimization framework

\section{concept 1}

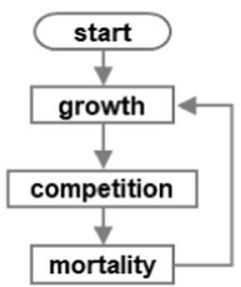

concept 2

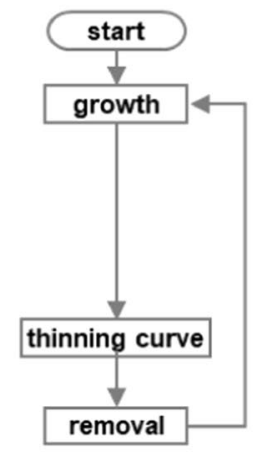

concept 4

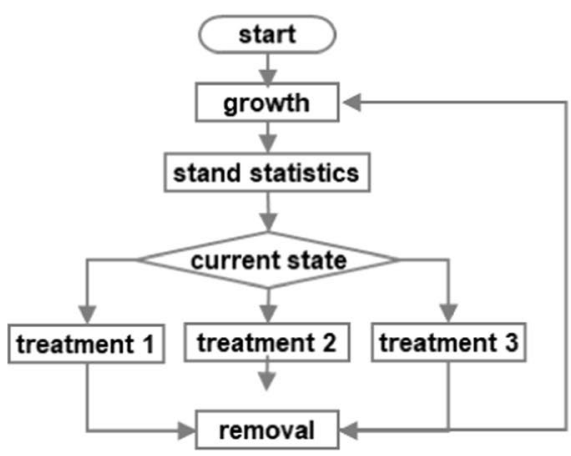

concept 6

\section{concept 3}

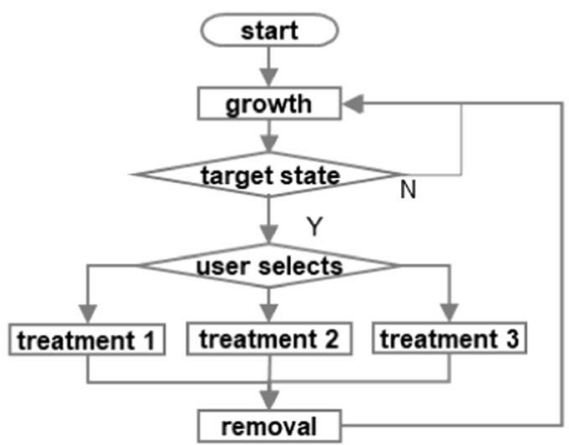

\section{concept 5}

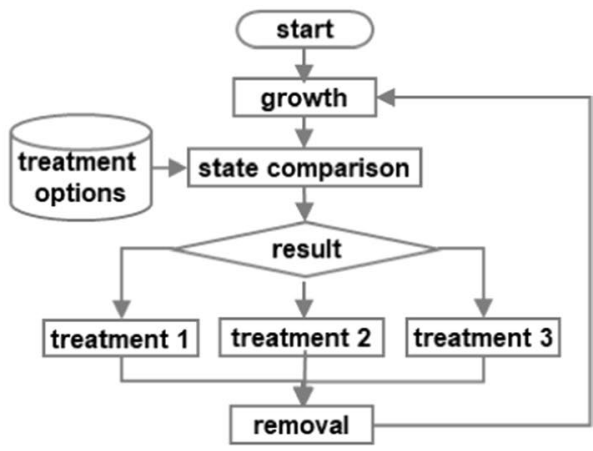

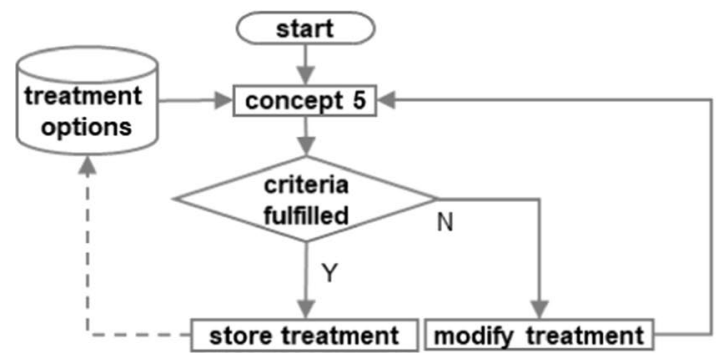

Publisher's Note Springer Nature remains neutral with regard to jurisdictional claims in published maps and institutional affiliations. 